
Brasileira 25: 365-370.

\title{
Produção de tubérculos de batata-semente em função das adubações nitrogenada, fosfatada e potássica
}

\author{
Gilberto Nava ${ }^{1}$; Antonio Roque Dechen ${ }^{2}$; Vera Lucia Iuchi ${ }^{1}$ \\ ${ }^{1}$ Epagri, EE São Joaquim, C. Postal 81, 88600-000 São Joaquim-SC; ${ }^{2}$ USP/ESALQ, Depto. Solos e Nutrição de Plantas, C. Postal 9, \\ 13418-900 Piracicaba-SP; nava@epagri.rct-sc.br
}

\section{RESUMO}

O trabalho foi realizado no município de São Joaquim, estado de Santa Catarina, em dois ciclos de cultivo (1999/00 e 2001/02), tendo como objetivo verificar o efeito da adubação nitrogenada, fosfatada e potássica na produtividade de tubérculos de batata-semente. O delineamento experimental foi de blocos ao acaso com quatro repetições. Foram testadas três doses de $\mathrm{N}_{\text {e }} \mathrm{K}_{2} 0(0 ; 150$ e $\left.300 \mathrm{~kg} \mathrm{ha}^{-1}\right)$ e quatro doses de $\mathrm{P}_{2} \mathrm{O}_{5}\left(0 ; 350 ; 700\right.$ e $\left.1050 \mathrm{~kg} \mathrm{ha}^{-1}\right)$. A produção de tubérculos foi afetada pela adubação nitrogenada e fosfatada e, dependendo do ciclo de cultivo, também pela potássica. O fósforo foi o nutriente que promoveu o maior incremento da produção de tubérculos. A batata respondeu a doses de 694 a $920 \mathrm{~kg} \mathrm{ha}^{-1}$ de $\mathrm{P}_{2} \mathrm{O}_{5}$, dependendo do ano de cultivo e da dose de nitrogênio envolvida. Essas quantidades foram superiores àquelas recomendadas oficialmente para os estados do Rio Grande do Sul e de Santa Catarina.

Palavras-chave: Solanum tuberosum, adubação, rendimento.

\begin{abstract}
Effect of the nitrogen, phosphorus and potassium fertilization on the potato tuber yield

This work was carried out in São Joaquim, Santa Catarina State, Brazil, in two cultivation cycles (1999/00 and 2001/02), to evaluate the effect of the nitrogen, phosphorus and potassium fertilization on the tuber yield of potato-seed. The experiment had a randomized block design with four replicates. Three levels of $\mathrm{N}$ and $\mathrm{K}_{2} \mathrm{O}(0 ; 150$ and $\left.300 \mathrm{~kg} \mathrm{ha}^{-1}\right)$ and four rates of $\mathrm{P}_{2} \mathrm{O}_{5}(0 ; 350 ; 700$ and $1050 \mathrm{~kg}$ ha $\left.{ }^{1}\right)$ were tested. The tuber production was affected by the nitrogen and phosphorus fertilization and, depending on the cultivation cycle, also by the potassium one. The yield was increased by $\mathrm{P}_{2} \mathrm{O}_{5}$ rates from 694 to $920 \mathrm{~kg} \mathrm{ha}^{-1}$ depending on the cultivation cycle and nitrogen rates. These amounts were higher than those recommended by the official institution for Santa Catarina and Rio Grande do Sul States.
\end{abstract}

Keywords: Solanum tuberosum, fertilization, yield.

(Recebido para publicação em 22 de março de 2006; aceito em 8 de agosto de 2007)

$\mathrm{N}$ o estado de Santa Catarina, devido a suas variadas condições de altitude e proximidade ao oceano, é possível cultivar-se batata durante o ano todo. O planalto sul de Santa Catarina é uma das regiões produtoras do estado onde o plantio de batata, principalmente com finalidade para semente, representa uma importante fonte de renda e trabalho. Os produtores de batata-semente, na grande maioria, adotam alta tecnologia para a obtenção de produtividade economicamente viável, sendo que entre os componentes dos custos de produção aparecem os fertilizantes, representando 24,1\% do custo total (Souza et al., 1999).

Os solos do planalto sul caracterizam-se principalmente pela elevada acidez e baixos teores de fósforo (P) disponível, o que torna necessária a aplicação de quantidades elevadas de fertilizantes. A alta capacidade de resposta da cultura da batata à adubação em comparação a outras culturas pode ser atribuída ao elevado potencial de produção, ao ciclo curto e ao sistema radicular re- lativamente superficial (Sangoi \& Kruse, 1994).

Face aos altos rendimentos, a extração de nutrientes é relativamente alta. Estima-se que para uma produtividade de 30 t ha $^{-1}$ de tubérculos, têm-se exportações aproximadas de $120 \mathrm{~kg}$ de potássio (K), 100 kg de nitrogênio (N) e 14 $\mathrm{kg}$ de fósforo (Reis Jr. \& Monnerat, 2001). No entanto, as quantidades dos diversos nutrientes absorvidos pela planta e extraídos pelos tubérculos dependem de uma série de fatores, entre os quais podem ser citados a região de cultivo, as condições climáticas, o manejo da cultura, a cultivar, o potencial de produção, entre outros (Sangoi \& Kruse, 1994).

Apesar do P ser menos extraído que o K e o N, os solos da região do planalto sul de Santa Catarina são naturalmente pobres em P. Além disso, no cultivo da batata, o pH do solo é limitado ao máximo de 5,5, uma vez que valores superiores estão associados à ocorrência de doenças como a sarna da batata (Sangoi \& Kruse, 1994). Em valores de
pH igual ou menores que 5,5 pode ocorrer alta fixação de $\mathrm{P}$ no solo e, conseqüentemente, a diminuição da disponibilidade deste nutriente para as plantas.

Jenkins \& Hakoomat (1999) observaram alta resposta da batata à adubação fosfatada e também observaram diferenças entre os cultivares, sendo que aqueles com sistema radicular limitado possuíam baixa capacidade de explorar os nutrientes do perfil do solo. O volume de raízes é particularmente importante para aqueles nutrientes que são relativamente imóveis no solo, tal como o P.

$\mathrm{O} \mathrm{K}$ é indispensável para a translocação de acúcares e síntese de amido (Reis Jr. \& Fontes, 1996), sendo o nutriente mais absorvido pela batata (Reis Jr. \& Monnerat, 2001). Embora o K seja importante para o aumento do rendimento de tubérculos (Moinuddin \& Bansal, 2005; Reis Jr. \& Fontes, 1996), o excesso pode reduzir o peso específico (Reis Jr. \& Fontes, 1996) e o teor de amido dos mesmos (Westermann et. al. 1994a).

O N é essencial para a formação da clorofila, proteína e muitas outras mo- 
léculas que atuam no desenvolvimento das plantas (Taiz \& Zeiger, 2004), sendo importante para manter um bom desenvolvimento da parte aérea e crescimento dos tubérculos (Westermann et al., 1994b).

A disponibilidade de N no solo é altamente dependente do teor de matéria orgânica (MO) e de sua taxa de mineralização. A atividade microbiana do solo é quem determina a taxa de mineralização e que por sua vez é dependente da temperatura, aeração e umidade do solo, entre outros fatores.

Visto ao grande número de reações químicas que o $\mathrm{N}$ sofre no solo, a obtenção de curvas de respostas em experimento de campo, ainda continua sendo a melhor forma para a calibração das doses de N. Atualmente, as adubações para a cultura da batata na região de São Joaquim são realizadas sem critérios pelos produtores, que adubam muitas vezes sem sequer realizar a análise química do solo. As formulações compostas de fertilizantes: fórmulas 5-20-10 e 4-14-8 são as mais utilizadas e as quantidades aplicadas chegam até a 4,0 t hä ${ }^{-1}$. $\mathrm{O}$ uso de maiores quantidades de fertilizantes que aquelas exigidas pelas plantas pode resultar no aumento do custo de produção e promover o desequilíbrio nutricional da planta, além de causar contaminação do ambiente. Assim, o objetivo deste trabalho foi avaliar a resposta da adubação nitrogenada, fosfatada e potássica sobre a produção da batata-semente para as condições do planalto sul de Santa Catarina e comparar com as quantidades desses nutrientes oficialmente recomendadas para esse estado.

\section{MATERIAL E MÉTODOS}

O experimento foi realizado no município de São Joaquim (SC) (28 ${ }^{\circ} 17^{\prime}$ 25" S, 49 56' 56" W) durante as safras de 1999/00 e 2001/02, sobre um Cambissolo Húmico alumínico. As áreas de plantio foram diferentes nos dois anos de avaliação, não havendo sobreposição de doses de fertilizantes e calcário. O preparo do solo foi iniciado cinco meses antes do plantio, com uma aração. Três meses antes do plantio aplicou-se 4 e 5,2 t ha-1 (solos usados na safra 1999/00 e 2001/02, respectivamente) de calcário dolomítico com PRNT de 75\% e realizou-se outra aração e uma gradagem. Por ocasião do plantio, efetuou-se nova gradagem e sulcamento da área experimental. A análise química do solo usado na safra 1999/2000 resultou: argila=460 $\mathrm{g} \mathrm{kg}^{-1}$; matéria orgânica=72 $\mathrm{g} \mathrm{kg}^{-1} ; \mathrm{pH}$ em água=4,6; $\mathrm{P}=3,8 \mathrm{mg} \mathrm{dm}^{-3}$; $\mathrm{K}=123 \mathrm{mg} \mathrm{dm}^{-3} ; \mathrm{Al}=61 \mathrm{mmol}_{\mathrm{c}} \mathrm{dm}^{-3}$; $\mathrm{Ca}=27 \mathrm{mmol} \mathrm{dm}_{\mathrm{c}}^{-3} ; \mathrm{Mg}=13 \mathrm{mmol}_{\mathrm{c}} \mathrm{dm}^{-3}$; e, na safra 2001/2002 resultou: argila=400 $\mathrm{g} \mathrm{kg}^{-1}$; matéria orgânica=62 g kg-1; pH em água =4,4; $\mathrm{P}=2,8 \mathrm{mg} \mathrm{dm}^{-3} ; \mathrm{K}=93$ $\mathrm{mg} \mathrm{dm}{ }^{-3} ; \mathrm{Al}=56 \mathrm{mmol}_{\mathrm{c}} \mathrm{dm}^{-3} ; \mathrm{Ca}=15$ $\mathrm{mmol}_{\mathrm{c}} \mathrm{dm}^{-3} ; \mathrm{Mg}=6 \mathrm{mmol}_{\mathrm{c}} \mathrm{dm}^{-3}$.

O delineamento experimental foi de blocos ao acaso com quatro repetições e a distribuição dos tratamentos se deu por meio do fatorial $3 \times 4 \times 3$. Os fatores em estudo foram três doses de N (0; 150 e $\left.300 \mathrm{~kg} \mathrm{ha}^{-1}\right)$, quatro doses de $\mathrm{P}(0 ; 350$; 700 e $1050 \mathrm{~kg} \mathrm{ha}^{-1}$ de $\mathrm{P}_{2} \mathrm{O}_{5}$ ) e três doses de $\mathrm{K}\left(0 ; 150\right.$ e $300 \mathrm{~kg} \mathrm{ha}^{-1}$ de $\left.\mathrm{K}_{2} \mathrm{O}\right)$. As fontes de nutrientes utilizadas foram o sulfato de amônio, cloreto de potássio e superfosfato triplo, para N, K e P, respectivamente. As doses de $\mathrm{P}$ e $\mathrm{K}$ foram integralmente aplicadas no plantio e as de $\mathrm{N}$ parceladas em duas vezes, sendo $50 \%$ no plantio e $50 \%$ em cobertura (30 dias após o plantio, por ocasião da amontoa).

O plantio foi realizado na primeira quinzena de dezembro, no primeiro ano e na primeira quinzena de novembro, no segundo ano, sendo utilizados tubérculos-semente do tipo III (diâmetro transversal entre 30 e $40 \mathrm{~mm}$ ) da cultivar "Monalisa”. Os tubérculos foram dispostos eqüidistantes nos sulcos, com o auxílio de réguas, espaçados a $20 \mathrm{~cm}$ na linha e $75 \mathrm{~cm}$ na entre linha. A parcela experimental foi constituída por 4 fileiras de plantio e 10 tubérculos em cada fila $\left(6 \mathrm{~m}^{2}\right)$. A cobertura dos tubérculos com solo foi efetuada manualmente, com auxílio de enxada. Após a emergência, as plantas receberam rigoroso controle fitossanitário, semelhante ao adotado pelos produtores, objetivando o controle de insetos e doenças. Os fungicidas utilizados foram principalmente Mancozeb e Chlorothalonil e os inseticidas Metramidofos e Malathion.

Na safra 1999/2000 houve falta de chuvas, principalmente na segunda quinzena após o plantio, o que tornou necessário a realização de duas irrigações durante este período. Na safra 2001/2002 houve uma boa distribuição de chuvas e não foi necessária a realização de irrigação.

Trinta dias após o plantio foi realizado a amontoa, com o auxílio de um arado aiveca de tração animal. Oitenta dias após o plantio procedeu-se a dessecação da parte aérea, utilizandose o herbicida Gramoxone (Glifosato). Três semanas após a morte da parte aérea realizou-se a colheita. Foram coletadas as duas fileiras centrais de cada parcela, exceto a última planta de cada extremidade. Assim, a área útil colhida foi de 2,4 $\mathrm{m}^{2}$ por parcela. Após o arranquio, os tubérculos foram transportados para a unidade de classificação, onde foram pesados.

Os dados foram avaliados por meio da análise de variância e regressão linear ao nível de 5\% de significância para delineamento experimental de blocos ao acaso e esquema de tratamentos fatorial, utilizando-se o programa SAS-system for windows (1996). Quando houve interação significativa entre os fatores, a mesma foi desdobrada para se estudar as combinações de interesse. Quando as equações foram quadráticas, obteve-se a dose de máxima eficiência técnica, a qual leva em conta somente a capacidade produtiva da planta, calculando-se a primeira derivada de cada equação.

\section{RESULTADOS E DISCUSSÃO}

O efeito das adubações sobre o rendimento foi diferenciado entre as safras, assim os dados foram analisados separadamente. Em nenhuma das safras houve interação tripla significativa entre as doses dos nutrientes (NxPxK). Da mesma forma, não foi evidenciada interação entre as doses de $\mathrm{N}$ e $\mathrm{K}$ ou entre as doses de $\mathrm{P}$ e $\mathrm{K}$.

Na safra 1999/2000, o rendimento de tubérculos não foi afetado pelas doses de $\mathrm{K}$ (dados não mostrados) o que deve estar relacionado ao elevado teor inicial (>120 mg kg-1 de K) deste nutriente no solo nesse ciclo de cultivo. Panique et al. (1997) também não observaram aumento no rendimento de tubérculos quando os teores de $\mathrm{K}$ 
trocável no solo estavam na faixa de 120 a $185 \mathrm{mg} \mathrm{kg}^{-1}$. Assim, mesmo considerando-se uma expectativa de rendimento alta, similar à produção obtida no presente trabalho, a adubação potássica pode ser desnecessária quando o teor inicial de K trocável do solo é elevado. No entanto, é importante ressaltar que neste estudo, a umidade do solo não foi um fator limitante para a absorção de $\mathrm{K}$, visto que irrigou-se sempre que necessário. Em situações que a umidade possa ser limitante, a resposta ao K também poderá ser diferente.

Em ambas as safras houve interação significativa entre a adubação nitrogenada e fosfatada, sendo que o fornecimento desses nutrientes aumentou a produção de tubérculos. Assim, os efeitos do $\mathrm{P}$ foram desdobrados dentro de cada dose de $\mathrm{N}$ e vice-versa.

Na safra 1999/2000, o aumento da produção de tubérculos em relação ao fornecimento de $\mathrm{P}$ seguiu o modelo quadrático, independente da dose de $\mathrm{N}$ utilizada (Figura 1a). As doses de $\mathrm{P}_{2} \mathrm{O}_{5}$ para a máxima eficiência técnica foram de 775; 820 e $690 \mathrm{~kg} \mathrm{ha}^{-1}$, para as doses zero, 150 e $300 \mathrm{~kg} \mathrm{ha}^{-1}$ de N, com produções de 23,6; 32,7 e 34,0 t ha-1 de tubérculos, respectivamente (Tabela 1). A produção de tubérculos obtida com a dose de $\mathrm{P}$ de máxima eficiência técnica para $300 \mathrm{~kg} \mathrm{ha}^{-1}$ de $\mathrm{N}\left(34,0 \mathrm{t} \mathrm{ha}^{-1}\right)$ foi aproximadamente $40 \%$ superior em relação àquela obtida na dose zero de $\mathrm{N}$ (23,6 t ha-1), evidenciando o efeito interativo entre o $\mathrm{N}$ e o $\mathrm{P}$.

A ausência da adubação fosfata limitou drasticamente o rendimento de tubérculos, principalmente na presença da dose mais alta de N. Neste caso, o rendimento de tubérculos foi aproximadamente $25 \mathrm{t} \mathrm{ha}^{-1}$ inferior ao obtido com a dose de máxima resposta de $\mathrm{P}_{2} \mathrm{O}_{5}(690$ $\mathrm{kg} \mathrm{ha}^{-1}$ ). Sangoi \& Kruse (1994) observaram um aumento do rendimento de tubérculos de batata semente até a dosagem de 2,8 t ha-1 da fórmula 5-20-10 (correspondente a $560 \mathrm{~kg}$ de P), em solo com características semelhantes ao do utilizado no presente trabalho. Embora os autores não tenham testado o efeito isolado de cada nutriente e sim, da fórmula N-P-K, possivelmente o P deve ter sido o elemento que mais influenciou o aumento de produção naquela situação.

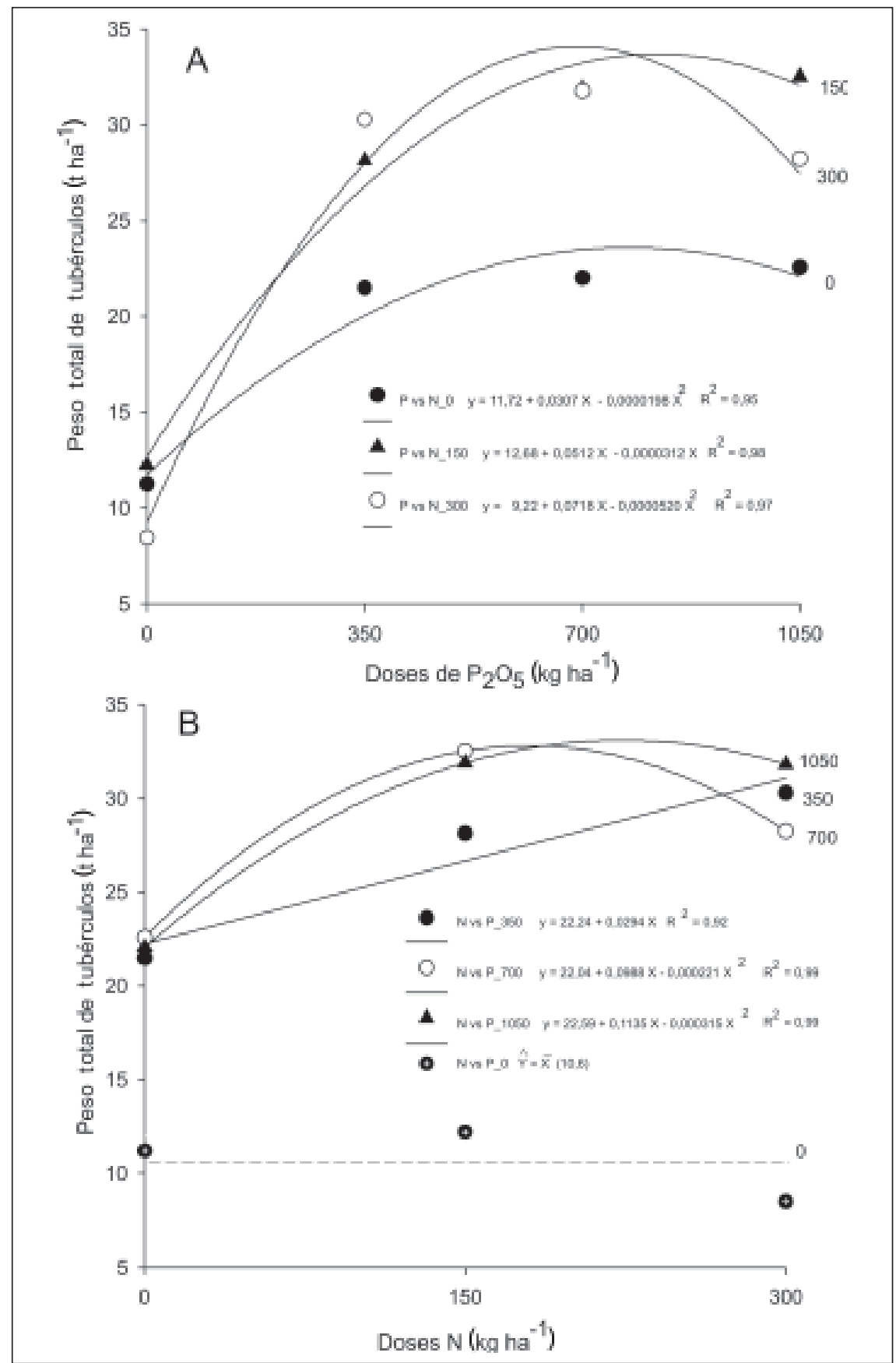

Figura 1. Produção de tubérculos de batata-semente na safra 1999/2000: (a) efeito da adubação fosfatada em cada dose de N; (b) efeito da adubação nitrogenada em cada dose de $\mathrm{P}$ (seed potato tuber yield obtained on the cultivation cycle 1999/2000: (a) effect of the P fertilization on each $\mathrm{N}$ dosis; (b) effect of $\mathrm{N}$ fertilization on each P dosis). São Joaquim, EPAGRI, 1999-2002.

Tabela 1. Doses de máxima eficiência técnica (DMET) de fósforo e respectivas produções máximas de tubérculo obtidas dentro de cada dose de nitrogênio na safra 1999/2000 (dosis of maximum technical efficiency (DMET) of $\mathrm{P}$ and the highest tuber yield obtained with each N dosis, cultivation cycle 1999/2000). São Joaquim, EPAGRI, 1999-2002.

\begin{tabular}{|c|c|c|}
\hline$N\left(k_{g ~ h a-1}\right)$ & $\begin{array}{c}\text { DMET } \\
\left(\mathrm{kg} \mathrm{ha-1} \text { de } \mathrm{P}_{2} \mathrm{O}_{5}\right) \\
\end{array}$ & $\begin{array}{c}\text { Produção máxima } \\
(\mathrm{t} \mathrm{ha-1})\end{array}$ \\
\hline 0 & 775 & 23,6 \\
\hline 150 & 820 & 32,7 \\
\hline 300 & 690 & 36,5 \\
\hline
\end{tabular}




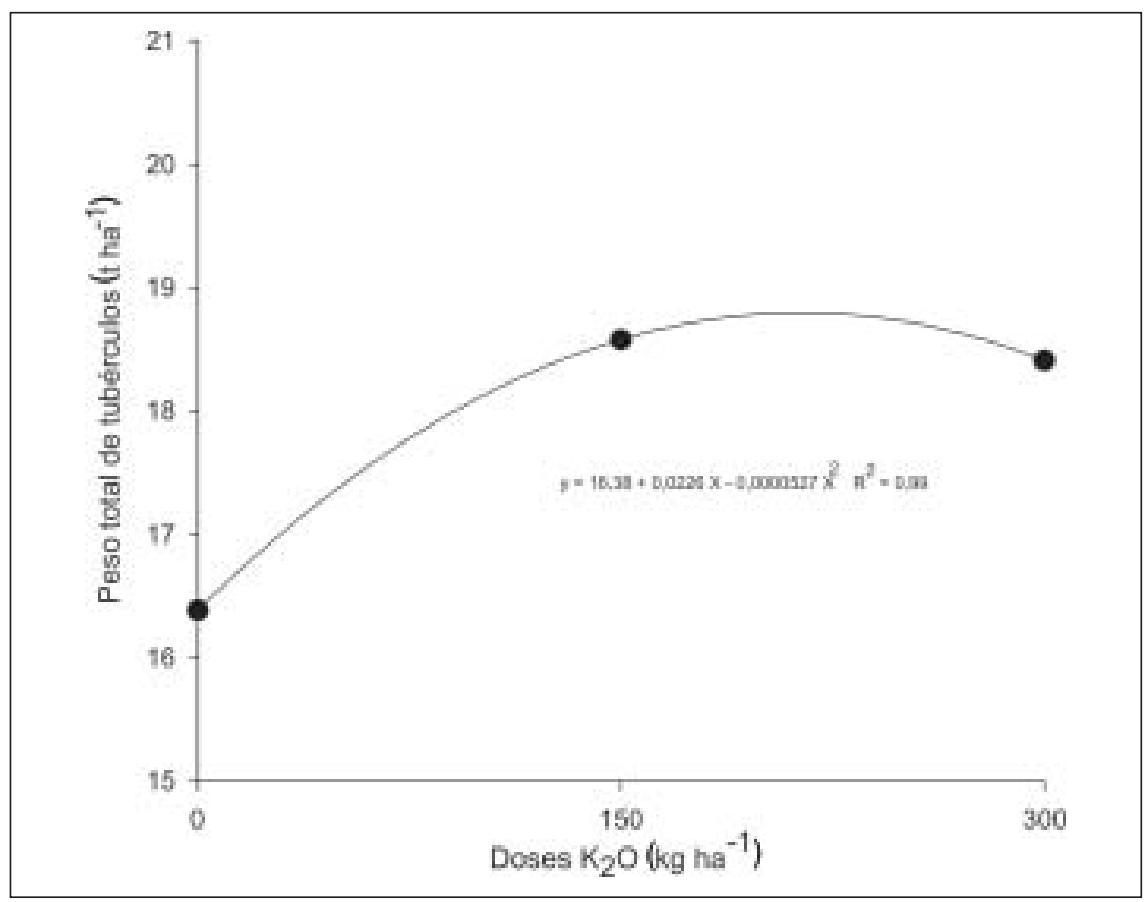

Figura 2. Produção de tubérculos de batata-semente na safra 2001/02 em função da adubação potássica (seed-tuber yield on the cultivation cycle 2001/2002, depending on the $\mathrm{K}$ fertilization). São Joaquim, EPAGRI, 1999-2002.

Tabela 2. Doses de máxima eficiência técnica (DMET) de fósforo e respectivas produções máximas de tubérculo obtidas dentro de cada dose de nitrogênio na safra 2001/2002 (dosis of maximum technical efficiency (DMET) of P and the highest tuber yield obtained with each N dosis, cultivation cycle 2001/2002). São Joaquim, EPAGRI, 1999-2002.

\begin{tabular}{|c|c|c|}
\hline $\mathbf{N}\left(\mathbf{k g ~ h a} \mathbf{~}^{-1}\right)$ & $\begin{array}{c}\text { DMET } \\
\left(\mathrm{kg} \mathrm{ha}^{-1} \text { de } \mathrm{P}_{2} \mathrm{O}_{5}\right) \\
\end{array}$ & $\begin{array}{c}\text { Produção máxima } \\
\left(\mathrm{t} \mathrm{ha}^{-1}\right)\end{array}$ \\
\hline 0 & 922 & 19,1 \\
\hline 150 & 816 & 24,5 \\
\hline 300 & 918 & 27,4 \\
\hline
\end{tabular}

Na safra 1999/2000, o rendimento de tubérculos foi afetado significativamente pelas doses de $\mathrm{N}$, com exceção de quando não se aplicou P. Nesta safra, houve uma resposta quadrática ao $\mathrm{N}$ nas doses de 700 e $1050 \mathrm{~kg} \mathrm{ha}^{-1}$ de $\mathrm{P} \mathrm{e}$ linear nas doses de $350 \mathrm{~kg} \mathrm{ha}^{-1}$ de P (Figura 1b). Quando as equações foram quadráticas, as doses para a máxima eficiência técnica foram de 224 e $180 \mathrm{~kg}$ ha $^{-1}$ de N, respectivamente. Resultados semelhantes foram mostrados por Sparrow \& Chapman (2003), que observaram aumento no rendimento de tubérculos até a dosagem de $193 \mathrm{~kg}$ de $\mathrm{N}$ ha${ }^{1}$ em solos cultivados há mais de dez anos com outras culturas. Sangoi \& Kruse (1994) observaram resposta no sistema de produção para batata-semente até a dosagem de 2,8 t ha-1 da formu- ram respostas à adubação potássica em solos com teores maiores que $120 \mathrm{mg}$ $\mathrm{kg}^{-1}$ de K trocável, porém, observaram que houve acréscimo no rendimento até a dosagem de $332 \mathrm{~kg} \mathrm{ha}^{-1}$ de K, em solos com teores de $\mathrm{K}$ trocável variando entre 75 a $110 \mathrm{mg} \mathrm{kg}^{-1}$. Westermann et al. (1994b) observaram acréscimo no rendimento de tubérculo (batata-consumo) até a dosagem de $448 \mathrm{~kg} \mathrm{ha}^{-1}$ de $\mathrm{K}$, independente da fonte de K utilizada.

Embora a adubação potássica tenha aumentado o rendimento de tubérculos, é recomendável a realização de estudos posteriores visando avaliar o efeito sobre a qualidade, uma vez que para determinadas cultivares, o excesso de $\mathrm{K}$ pode reduzir o teor de amido dos tubérculos (Westermann et al. 1994a), o que pode influenciar na capacidade de germinação dos mesmos.

A exemplo do que ocorreu na primeira safra, no ciclo 2001/2002 houve interação significativa entre as doses de N e P. Nesta safra, o aumento da produção de tubérculos em relação ao fornecimento de P seguiu o modelo quadrático, independente da dose de $\mathrm{N}$ utilizada (figura 3a). As doses de $\mathrm{P}_{2} \mathrm{O}_{5}$ para a máxima eficiência técnica foram de 922, 816 e $918 \mathrm{~kg} \mathrm{ha}^{-1}$, para as doses zero, 150 e $300 \mathrm{~kg} \mathrm{ha}^{-1}$ de N, com produções em resposta às doses de $\mathrm{P}$ de 19,1; 24,5 e 27,4 t ha $^{-1}$, respectivamente (Tabela 2). As máximas produções desta safra foram inferiores àquelas da safra 1999/2000 o que pode estar relacionado a condições climáticas desfavoráveis como o excesso de chuvas que ocorreu, o que pode ter lixiviado, principalmente o N. Com a dose mais alta de $\mathrm{N}$ (300 kg ha-1), calculou-se que a produção aumentou quase 20 t ha-1 ${ }^{-1}$ com a aplicação da dose de máxima eficiência técnica de $\mathrm{P}$, evidenciando mais uma vez que o $\mathrm{P}$ foi o nutriente que proporcionou o maior acréscimo na produção de tubérculos. Observa-se que a dose de $\mathrm{P}_{2} \mathrm{O}_{5}$ poderia ser reduzida de 922 para $816 \mathrm{~kg} \mathrm{ha}^{-1}$ (106 kg a menos) se a dose de $\mathrm{N}$ passasse de zero para $150 \mathrm{~kg}$ ha $^{-1}$, assegurando ainda um aumento de 28\% na produção de tubérculos. Assim, dependendo do preço por unidade de cada nutriente, outras combinações entre $\mathrm{N}$ e $\mathrm{P}$ podem ser adotadas.

Os resultados obtidos evidenciam que a cultura da batata responde em ter- 
mos de rendimento a doses de $\mathrm{P}$ muito superiores que aquelas adotadas para as culturas anuais em geral. O sistema radicular pequeno e superficial e o ciclo curto da cultura podem estar relacionados com a alta exigência em $P$ para a batata-semente.

Na safra 2001/2002, o rendimento total de tubérculos não foi afetado significativamente pelas doses de $\mathrm{N}$ quando não se adubou com $P$, porém, houve uma resposta linear às doses de $\mathrm{N}$ dentro das demais doses de $\mathrm{P}$, o que indica que a dose máxima de $\mathrm{N}$ utilizada no presente trabalho foi insuficiente para a obtenção do máximo rendimento de tubérculos (Figura 3b). Assim, novos estudos devem ser realizados, visando observar melhor a relação entre a adubação nitrogenada e o rendimento de tubérculos, visto que na safra 1999/2000 somente houve incremento no rendimento até a dosagem de $200 \mathrm{~kg}_{\mathrm{ha}}{ }^{-1}$ de N. O menor teor de matéria orgânica do solo e, possivelmente, a maior lixiviação do $\mathrm{N}$ (ano de maior volume de precipitações pluviométricas) na safra 2001/ 2002 podem estar relacionados com os diferentes valores de resposta obtidos nesta safra e aqueles da safra 1999/2000.

Baseado nos resultados da análise inicial do solo, a recomendação de adubação oficial para os estados de Santa Catarina e Rio Grande do Sul (SBCSComissão de Química e Fertilidade do Solo, 2004) sugere para uma expectativa de rendimento superior a $20 \mathrm{t} \mathrm{ha}^{-1}$, doses de 120; 280 e $140 \mathrm{~kg} \mathrm{ha}^{-1}$ de $\mathrm{N}$, $\mathrm{P}_{2} \mathrm{O}_{5}$ e $\mathrm{K}_{2} \mathrm{O}$, respectivamente para a safra 1999/2000 e 120; 360 e $140 \mathrm{~kg} \mathrm{ha}^{-1}$ de $\mathrm{N}, \mathrm{P}_{2} \mathrm{O}_{5}$ e $\mathrm{K}_{2} \mathrm{O}$ para a safra 2001/ 2002. Esses valores são inconsistentes, principalmente com relação à adubação fosfatada, que na safra 1999/2000 seria subestimada em até 65,9\% (considerando a dose máxima eficiência técnica de $820 \mathrm{~kg} \mathrm{ha}^{-1}$ de $\mathrm{P}_{2} \mathrm{O}_{5}$ obtida nesta safra). Para a safra 2001/2002, a dose recomendada pela SBCS seria subestimada em até $60,9 \%$ (considerando a dose máxima de eficiência técnica de $920 \mathrm{~kg} \mathrm{ha}^{-1}$ de $\mathrm{P}_{2} \mathrm{O}_{5}$ ) Quando a produção de tubérculos atingiu um valor máximo em função das doses de $\mathrm{N}$ e K, observa-se que a adubação nitrogenada (safra 1999/2000) também foi subestimada em aproximadamente $46 \%$ e a adubação potássica (sa-

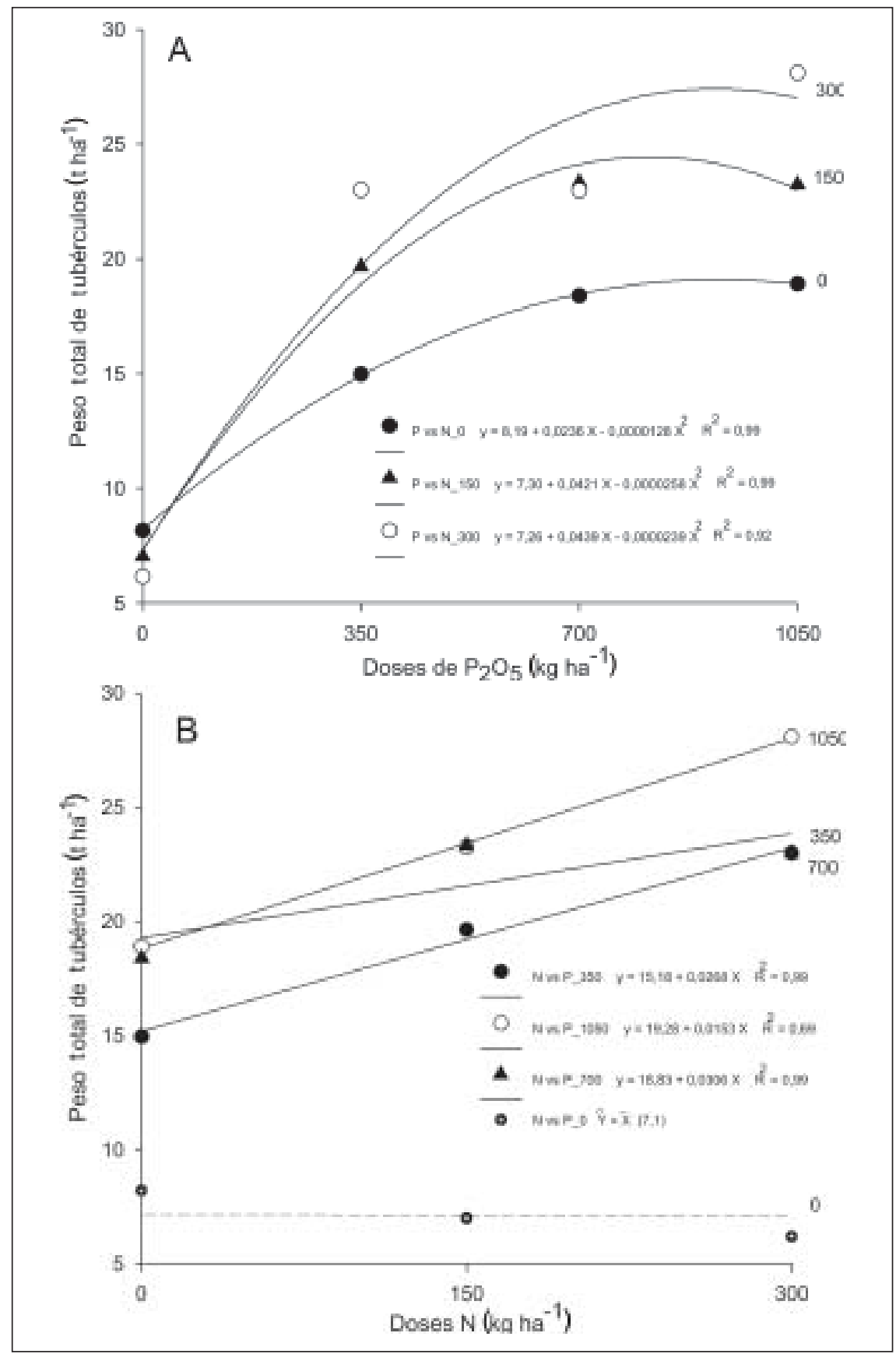

Figura 3. Produção de tubérculos de batata-semente na safra 2001/02: (a) efeito da adubação fosfatada em cada dose de N; (b) efeito da adubação nitrogenada em cada dose de $\mathrm{P}$ (seed-tuber yield on the cultivation cycle 2001/2002: (a) effect of the P fertilization on each $\mathrm{N}$ dosis; (b) effect of $\mathrm{N}$ fertilization on each P dosis)). São Joaquim, EPAGRI, 1999-2002.

fra 2001/2002) em aproximadamente $35 \%$, em relação às doses de máxima eficiência técnica obtidas no presente trabalho. No entanto, a recomendação de K pela SBCS para a safra 1999/2000 seria superestimada, se observada a não resposta ao nutriente nesta safra.

Em trabalhos futuros torna-se fundamental, também a avaliação de aspectos econômicos da cultura, visto que no presente trabalho, a análise dos resultados limitou-se a avaliar a máxima capacidade produtiva da cultura em função das adubações. Porém, a grande flutuação dos preços da batata e dos fertilizantes no decorrer dos anos deixa a extrapolação de resultados desta natureza um tanto arriscada.

Os resultados obtidos permitem concluir que: o fornecimento de $\mathrm{P}$ foi o que 
possibilitou o maior incremento na produção de tubérculos de batata-semente. A cultura da batata-semente respondeu em termos de produção de tubérculos a doses de até $920 \mathrm{~kg} \mathrm{ha}^{-1}$ de $\mathrm{P}_{2} \mathrm{O}_{5}$; o rendimento de tubérculos aumentou em função da adubação nitrogenada até a dosagem de $224 \mathrm{~kg} \mathrm{ha}^{-1}$ na safra 1999/ 2000 e linearmente na safra 2001/2002; a resposta da cultura da batata ao potássio depende do nível inicial deste elemento no solo e somente ocorreu na última safra até a dosagem de $214 \mathrm{~kg} \mathrm{ha}^{-1}$ de $\mathrm{K}_{2} \mathrm{O}$; a resposta da cultura da batatasemente a $\mathrm{P}$ e $\mathrm{N}$ ocorreu até doses superiores que aquelas recomendadas oficialmente para os estados do Rio Grande do Sul e Santa Catarina; a resposta a K se deu até doses superiores que as recomendadas para a safra 2001/ 2002, porém, não houve resposta à adubação potássica na safra 1999/2000, quando oficialmente se recomenda aplicar $140 \mathrm{~kg} \mathrm{ha}^{-1}$.

\section{REFERÊNCIAS}

Comissão de Química e Fertilidade do Solo. 2004 Manual de adubação e calagem para os estados do Rio Grande do Sul e de Santa Catarina; SBCS-NRS: Brasil, 10 ed., Porto Alegre, 400p.
JENKINS P D; ALI H. 1999. Growth of potato cultivars in response to application of phosphate fertilizer. Annals of Applied Biology 135: 431-438.

JOERN BC; VITOSH ML. 1995. Influence of applied nitrogen on potato.1. yield, quality, and nitrogen uptake. American Potato Journal 72: 51-63.

MOINUDDIN US. 2004. Influence of combined application of potassium and sulfur on yield, quality, and storage behavior of potato. Communications in Soil Science and Plant Analysis 35: 1047-1060.

MOINUDDIN SK; BANSAL SK; PASRICHA NS. 2004. Influence of graded levels of potassium fertilizer on growth, yield, and economic parameters of potato. Journal of Plant Nutrition 27: 239-259.

MOINUDDIN SK; BANSAL SK. 2005. Growth, yield, and economics of potato in relation to progressive application of potassium fertilizer. Journal of Plant Nutrition 28: 183-200.

OLIVEIRA CAS. 2000. Potato crop as afected by nitrogen and plant density. Pesquisa Agropecuária Brasileira 35: 939-950.

PANIQUE E; KELLING KA; SCHULTE EE; HERO DE; STEVENSON WR; JAMES RV. 1997. Potasium rate and source effects on potato yied, quality, and disease interaction, American Potato Journal 74: 379-398.

REIS JÚNIOR RA; FONTES CR. 1996. Qualidade de tubérculos de batata em função de doses da adubação potássica. Horticultura Brasileira 14: 170-174.

REIS JÚNIOR RA; MONENERAT PH. 2000. Nutrient concentrations in potato stem petiole and leaflet in response to potassium fertilizer. Scientia Agrícola 57: 251-255.
REIS JÚNIOR, RA.; MONNERAT PH. 2001. Exportação de nutrientes nos tubérculos de batata em função de doses de sulfato de potássio. Horticultura Brasileira 19: 360-364.

SANGOI L; KRUSE ND. 1994. Doses crescentes de nitrogênio, fósforo e potássio e características agronômicas da batata em dois níveis de pH. Pesquisa Agropecuária Brasileira 29: 1331-1343.

SAS INSTITUTE. 1996. The SAS-system for windows: release 6.08 SAS Institute: Cary, NC, 633p.

SOUZA ZS; SILVA ACF; BEPPLER NETO R. 1999. Cadeias produtivas do estado de Santa Catarina: batata. Florianópolis: Epagri, 84p. (Epagri. Boletim técnico, 104).

SPARROW LA; CHAPMAN KSR. 2003. Effects of nitrogen fertilizer on potato (Solanum tuberosum L., cv. Russet Burbank) in Tasmania. 1. Yield and quality. Australian Journal of Experimental Agriculture 43: 631641

TAIZ Z; ZEIGER E. 2004. Fisioligia vegetal. 3 ed. Porto Alegre: Artmed, 719p.

WESTERMANN DT; TINDALL TA; JAMES DW; TINDALL TA; HURST RL. 1994a. Nitrogen and potassium fertilization on potatoes - sugars and starch. American Potato Journal 70: 433-454.

WESTERMANN DT; TINDALL TA; JAMES DW; HURST RL. 1994b. Nitrogen and potassium fertilization on potatoes - yield and specific gravity. American Potato Journal 71: 417-431. 